\title{
Electrofusion of in vitro produced bovine embryonic cells for the production of isofusion contours for cells used in nuclear transfer
}

\author{
B. G. Tatham ${ }^{1}$, D. A. Pushett ${ }^{1}$, K. J. Giliam ${ }^{1}$, A. T. Dowsing ${ }^{1}$, \\ T. L. Mahaworasilpa ${ }^{2}$ and A. O. Trounson ${ }^{1}$ \\ ${ }^{I}$ Laboratories of Human and Animal Reproductive Biology, Institute of Reproduction and \\ Development, Monash University, Melboume; and ${ }^{2}$ UNESCO Centre for Membrane and Science \\ Teclnology, Department of Biophysics, University of NSW, Sydney, Australia
}

\section{Introduction}

Electrofusion is a reliable method of inducing cell to cell fusion. It can be used for a variety of purposes, including nuclear transfer for the production of identical progeny and hybridoma production for monoclonal antibody production. Electrofusion involves the combination of alternating current $(\mathrm{AC})$ and direct current (DC) pulses to induce membrane fusion. An AC pulse induces cell alignment and dielectrophoresis, which causes tight membrane contact (Mahaworasilpa et al., 1994). The DC pulse results in point membrane fusion and the formation of an unstable flat membrane diaphragm, where spectrin holds lipid fragments together. Although cytoplasm can move between the cells through the pores of a flat membrane diaphragm, large organelles such as mitochondria and nuclei remain contained in the original cell. Under favourable conditions, the flat diaphragm deteriorates to allow cell mixing, indicating true cell to cell fusion (Chernomordik and Sowers, 1991).

Electrical parameters for successful electrofusion rely on the amplitude and duration of the DC pulse. Cell mixing occurs when these parameters are of sufficient magnitude to prevent the flat diaphragm from reforming the membrane lipid bilayers. Other factors that influence cell mixing are temperature, $\mathrm{pH}$ and molecules such as cholesterol and ethylmaleimide (A. Sowers, personal communication).

An isofusion contour describes the electrofusion characteristics of a particular cell type and its membranes. A range of DC pulse amplitudes and durations are used to attempt electrofusion of identical cells of equal diameter and of a particular type. The maximum electrofusion result for each pulse duration can be used to construct an isofusion contour. The isofusion contours for different cell types can be compared to predict the optimal electrofusion parameters for fusion between them (Mahaworasilpa, 1992).

This study investigated the electrofusion of identical cell types to produce isofusion contours for cells used for nuclear transfer. The cells used were bovine oocytes matured in vitro, oocytes enucleated using two different centrifugation treatments and blastomeres isolated from embryos 3, 4, 5 and 6 days after in vitro fertilization (IVF).

\section{Materials and Methods}

Bovine ovaries were collected from an abattoir and washed in $0.9 \%(\mathrm{w} / \mathrm{v})$ saline, before germinal vesicle stage oocytes were aspirated from follicles. Cumulus-oocyte complexes were matured in a humidified atmosphere of $5 \% \mathrm{CO}_{2}$ in air for $24 \mathrm{~h}$ in tissue culture medium 199 (TCM 199; Sigma, St Louis, MO) with $10 \%$ (v/v) fetal calf serum (FCS; PA Biologicals, Sydney), 0.01 iu bovine pituitary FSH $\mathrm{ml}^{-1}$ and 0.01 iu bovine pituitary $\mathrm{LH} \mathrm{ml}^{-1}$ (NOBL Laboratories, Sioux Centre, LA). Cumulus cells were removed from matured oocytes by vortexing and the zona pellucida was removed from oocytes that had 

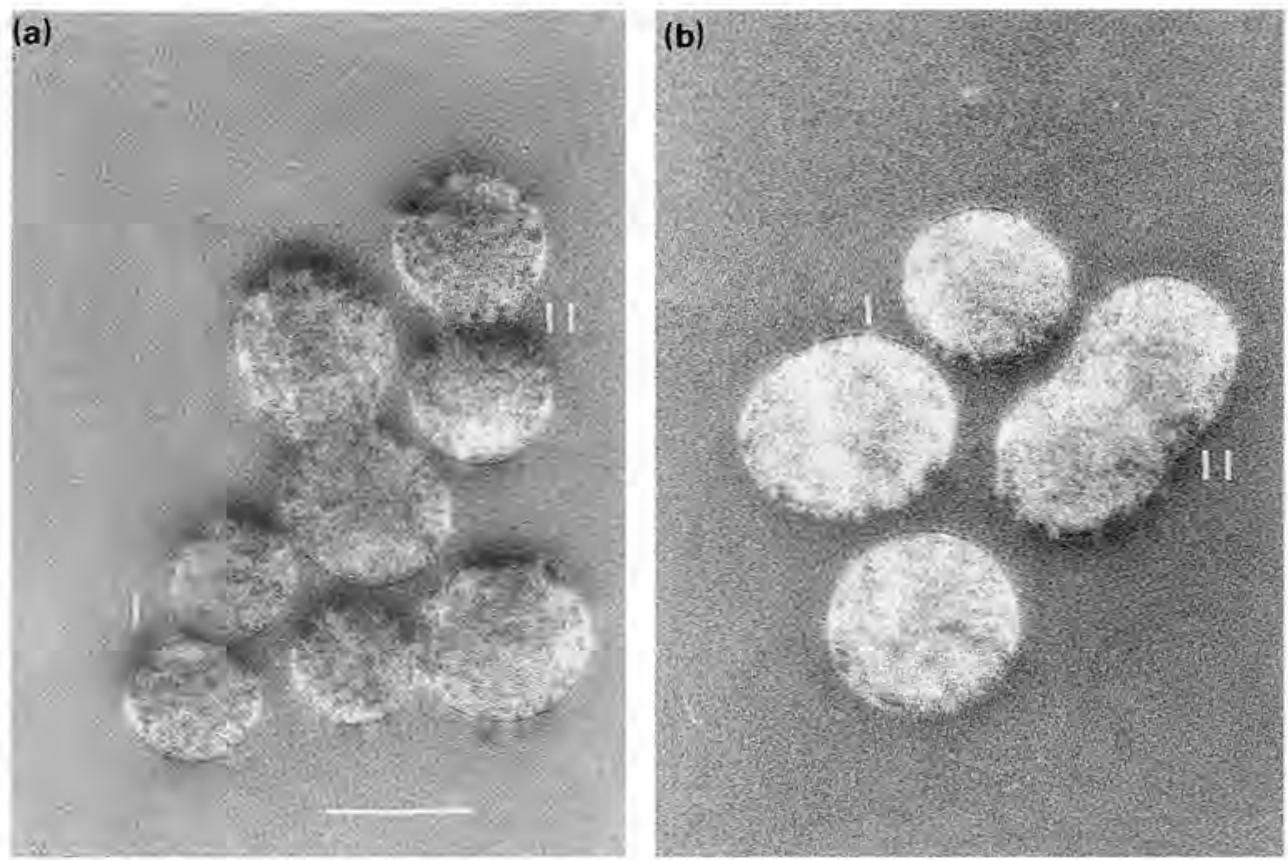

Fig. 1. Electrofusion of coupled blastomeres isolated from bovine embryos produced after in vitro fertilization, showing (a) blastomeres with (I) a point membrane fusion, which has progressed to form (II) a flat membrane diaphragm $3 \mathrm{~min}$ after pulsation. The membrane diaphragm (b) may either (I) facilitate membrane stabilization, failed fusion and cell separation, or (II) deteriorate to allow cell mixing and true cell fusion $15 \mathrm{~min}$ after pulsation. (Scale bar represents $25 \mu \mathrm{m}$.)

extruded the first polar body using $0.5 \%$ pronase (w/v) (Sigma, St Louis, MO) before being enucleated by centrifugation or used in electrofusion experiments.

Mature oocytes were enucleated with two different centrifugation treatments (Tatham et al., 1995). The zona was removed from oocytes that were placed into a Percoll density gradient of $7.5,30$ and $45 \%$ $(\mathrm{v} / \mathrm{v})$ isotonic Percoll, containing $10 \mu \mathrm{g}$ cytochalasin B ml ${ }^{-1}$ (Sigma, St Louis, MO) in a $0.4 \mathrm{ml}$ centrifuge tube (Eppendorf). Oocytes were centrifuged for $4 \mathrm{~s}$ at $5000 \mathrm{~g}$. The second treatment involved centrifugation of the matured oocytes with the zona intact for 2 min at $15000 \mathrm{~g}$ before the zona was removed and the oocytes enucleated as above. Oocyte fragments that did not produce an extrusion cone $6 \mathrm{~h}$ after centrifugation were considered enucleated and used for electrofusion experiments (Tatham et al., 1993).

Spermatozoa were prepared using a modified mini-Percoll density gradient (Ord et al., 1990) that consisted of $1.0 \mathrm{ml}$ each of 50,70 and $90 \%$ isotonic Percoll (Sigma, St Louis, MO) in TALP medium (Bavister, 1989) with $10 \mathrm{mmol}$ Hepes $1^{-1}$ (Calbiochem, La Jolla, CA) and $6.0 \mathrm{mg} \mathrm{BSA} \mathrm{ml}{ }^{-1}$ (Miles Pentex, Kankakadee, IL). Spermatozoa were added to groups of ten oocytes to give a final concentration of $2 \times 10^{6}$ spermatozoa $\mathrm{ml}^{-1}$ in a total volume of $50 \mu \mathrm{l}$. After fertilization for $22 \mathrm{~h}$, the cumulus was removed and groups of four zygotes were cultured in $30 \mu \mathrm{l}$ microdrops of modified synthetic oviduct fluid medium (Gardner et al., 1994) covered with mineral oil. The embryos were transferred into fresh $30 \mu \mathrm{l}$ microdrops of culture medium every $48 \mathrm{~h}$ until the embryos were required for electrofusion experiments. The zonae pellucidae of the embryos were removed and the blastomeres disaggregated in TALP with BSA and without $\mathrm{Ca}^{2+}$ or $\mathrm{Mg}^{2+}$.

Before electrofusion, the embryonic cells were equilibrated for $10 \mathrm{~min}$ with four washes in $50 \mu \mathrm{l}$ drops of fusion medium covered with mineral oil. Fusion medium consisted of 0.25 mol sucrose $1^{-1}$ buffered to $\mathrm{pH} 7.4$ with $1.0 \mathrm{~mol}$ Hepes $\mathrm{I}^{-1}$ or $1.0 \mathrm{~mol}$ Trisma acetate $\mathrm{I}^{-1}$ (Sigma, St Louis, MO). Pairs of identical cells were placed in the fusion chamber, consisting of two parallel stainless steel wires of $0.5 \mathrm{~mm}$ diameter and separated by $0.5 \mathrm{~mm}$ (BTX microslide 450; BTX, San Diego, CA) and covered with 


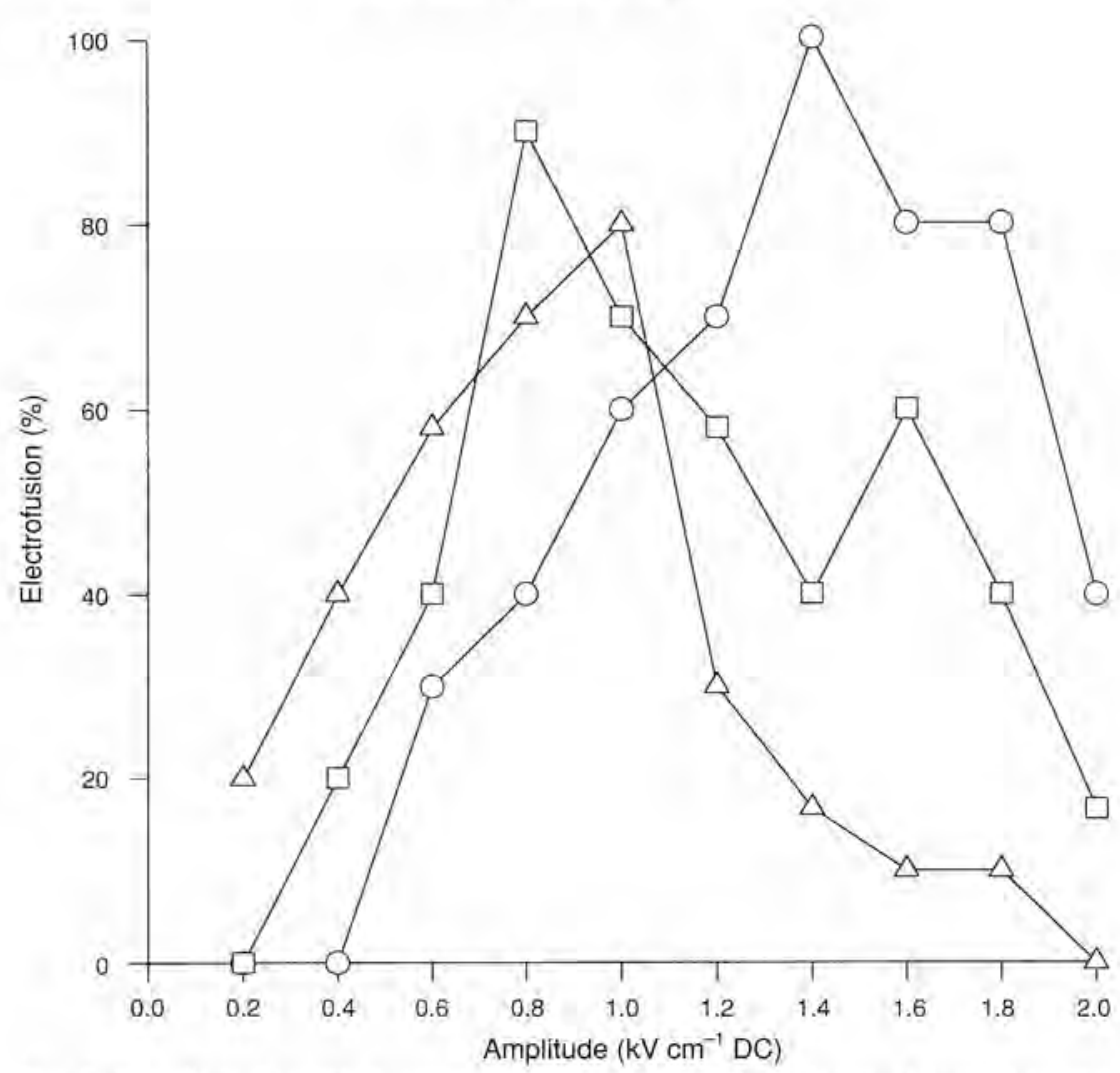

Fig. 2. The effect of amplitude and pulse duration on the electrofusion of coupled in vitro matured bovine oocytes that have been enucleated using two centrifugation treatments. Pulse duration of (O) $10 \mu \mathrm{s}$; ( $\square$ ) $50 \mu \mathrm{s}$; and $(\Delta) 100 \mu \mathrm{s}$.

fusion medium. Cell alignment and dielectrophoresis were achieved using an AC pulse of 8 volts amplitude for $5 \mathrm{~s}$. Point membrane fusion was then attempted on the electrodes with a single DC pulse of $0.2-2.0 \mathrm{kV} \mathrm{cm}-1$ and of 10,50 and $100 \mu$ s duration, using a Zimmerman Fusion Machine (Precision Scientific, Chicago, IL). After electrical treatment, cells were placed on a warm stage and cell fusion assessed $15 \mathrm{~min}$ later. Successful fusion was defined as the breakdown of a flat membrane diaphragm that allowed cell mixing. For each cell type, electrofusion was attempted on ten pairs of cells with a minimum of three replicates for the three pulse durations, each with ten different amplitudes.

Electrofusion results were subjected to statistical analysis of variance using the SAS (SAS, 1985) general linear model procedure. The results for each cell type were graphically represented with respect to pulse amplitude and duration. Isofusion contours were then constructed using the optimal electrofusion parameters (i.e., the current at which maximum electrofusion was achieved for a given pulse duration)

\section{Results}

The production of isofusion contours for each cell type relied on cell mixing as a measure of successful cell fusion. Point membrane fusion was induced by the DC pulse, and extended to form a flat membrane diaphragm, which then dispersed to allow cell fusion and cell mixing (Fig. I).

Electrofusion attempts of all different cell types resulted in a significant increase $(P<0.05)$ in fusion when a $10 \mu \mathrm{s}$ pulse was used compared with a 50 or $100 \mu$ s pulse $(52 \%$ versus $41 \%$ and $36 \%$, 


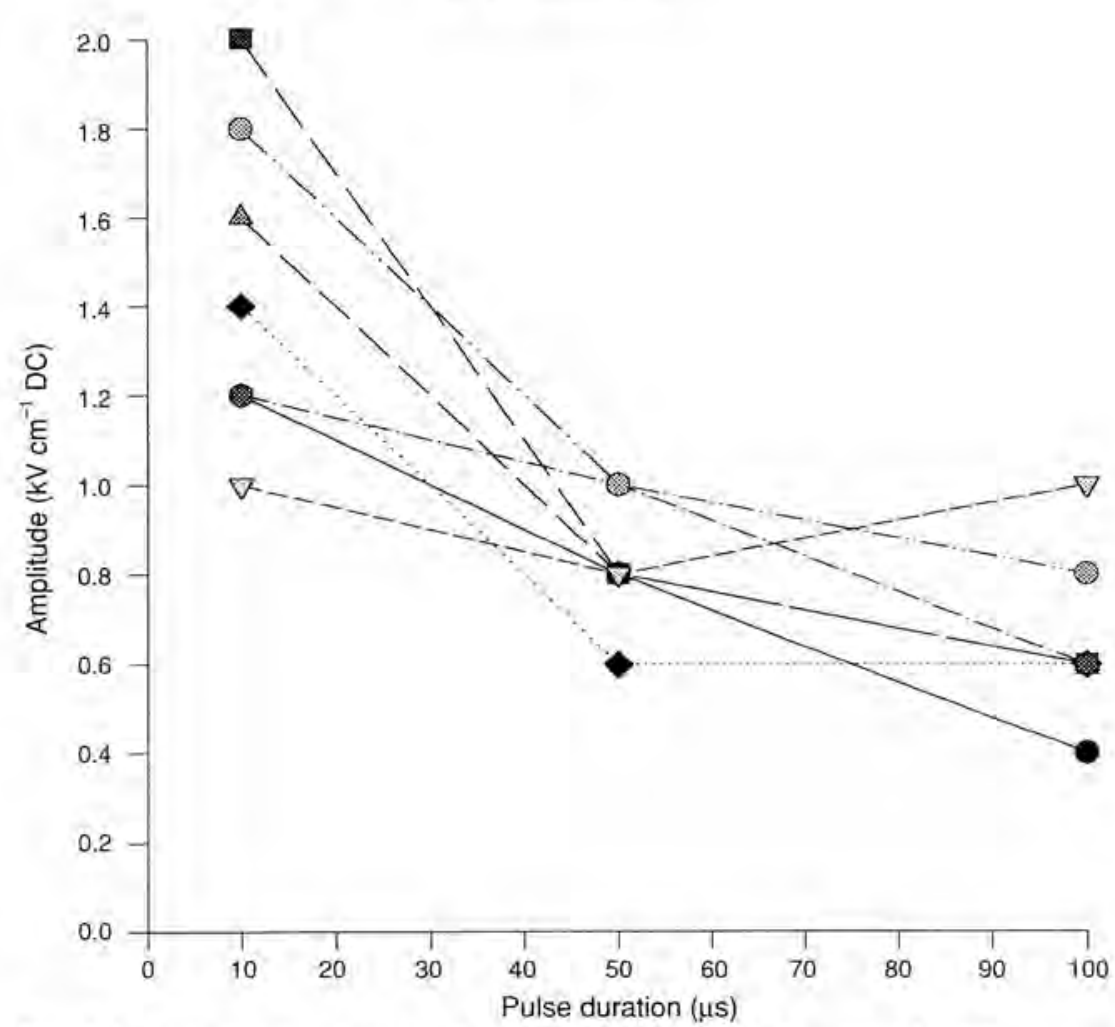

Fig. 3. Isofusion contours produced after electrofusion of (-) coupled bovine oocytes: coupled oocytes enucleated by $(\boldsymbol{D})$ one and $(\Delta)$ two centrifugation treatments; and, coupled blastomeres from embryos $(\nabla) 3,(\diamond) 4,(\otimes) 5$ and $(\circlearrowleft) 6$ days after in vitro fertilization.

respectively). The electrofusion of all cell types was significantly increased $(P<0.05)$ with a single $50 \mu \mathrm{s}$ DC pulse greater than $1.0 \mathrm{kV} \mathrm{cm}^{-1}$ than when an amplitude below $1.0 \mathrm{kV} \mathrm{cm}^{-1}$ was used $(55 \%$ versus $33 \%)$.

The electrofusion results for each cell type showed a similar pattern (Fig. 2), from which the maximum fusion amplitude for each pulse duration was selected to create an isofusion contour. The slight differences between each contour represented the differences in the electrofusion characteristics of the cells and membranes (Fig. 3), in which the isofusion contours of all the cell types are compared. The optimum parameters for electrofusion of two different cell types can be determined by selecting the point where the isofusion contours for each cell type intersect. When isofusion contours do not intersect, electrofusion parameters can be determined by taking the median at the point where the contours are closest.

\section{Discussion}

In this study, the use of a short DC pulse at an amplitude greater than $1.0 \mathrm{kV} \mathrm{cm}^{-1}$ resulted in significantly greater electrofusion of identical cells when compared with longer pulse durations of greater amplitudes. This may result from high amplitude DC pulses of short duration creating smaller pores in the opposing cell membranes and causing less damage to membrane integrity $(\mathrm{H}$. Coster, personal communication).

The variation between the isofusion contour gradients reflects the differences between cell types. The different cell types do not have identical membrane composition or diameter, owing to a decreased blastomere diameter with age and changes in lipid and protein composition as development progresses (Barnes and Eyestone, 1990). 
Isofusion contours graphically describe the characteristics of cell membranes. Where isofusion contours intersect, the electrofusion properties of different cell types and their membranes approach each other. This provides a simple method for determining the optimal electrofusion parameters for different cell types. The cell types used in this study are used for nuclear transfer in our laboratory, where we are investigating the electrofusion of blastomeres with enucleated oocytes using electrofusion parameters predicted with the aid of isofusion contour interactions.

The authors wish to acknowledge the support of Genetics Australia Co-operative Society Ltd. This study was funded by a grant from the Australian Government Research and Development Board.

\section{References}

Barnes FL and Eyestone WH (1990) Early cleavage and the maternal zygotic transition in bovine embryos Theriogenology 33 141-152

Bavister BD (1989) A consistently successful procedure for in vitro fertilization of golden hamster eggs Gamete Research $23 \quad 139-158$

Chernomordik LV and Sowers AE (1991) Physical and ultrastructural evidence that integrin of the spectrin network controls the macroscopic fusion produce morphology following the electrotusion of erythrocyte ghosts Biophysical Journal 60 $1026-1037$

Gardner DK, Lane M, Spitzer A and Batt PA (1994) Enhanced rates of cleavage and development for sheep zygotes cultured to the blastocyst stage in vitro in the absence of serum and somatic cells: amino acids vitamins and culturing embryos in groups stimulate development Biology of Reproduction 50 390-400
Mahaworasilpa TL (1992) Cell Electro-dynamics: the Mechanisms of Living Cells in Intense Alternating Electric Fields PhD Thesis, University of NSW

Mahaworasilpa TL, Coster HGL and George EP (1994) Forces on biological cells due to applied alternating $(\mathrm{AC})$ electric tields. I Dielectrophoresis Biochimica et Biophysica Acta $1193118-126$

Ord T, Patrizio P, Marello E, Balmaceda JP and Asch RH (1990) Mini-Percoll: a new method of semen preparation for IVF in severe male factor infertility Human Reproduction 5 $987-989$

SAS Institute Inc. (1985) SAS Users Giaide: Basics Version 5. Cary, NC

Tatham BG, Dowsing AT and Trounson AO (1993) Enucleation by centrifugation for bovine nuclear transplantation Prociedings of the Australian Society for Reproductive Biology 2531 